\title{
Preoperatif MPV, KABGO sonrası Serebrovasküler Olay için prediktör olabilir mi?
}

\author{
May Preoperative MPV predictor for Cerebrovascular Event After CABG? \\ Fatih Aygün*, Mehmet Özüllü, Murat Günday \\ Kalp ve Damar Cerrahisi Anabilim Dalı (Dr. F. Aygün, Dr. M. Özülkü, Dr. M. Günday), Başkent \\ Üniversitesi Konya Araştırma ve Uygulama Merkezi, TR-42000 Konya
}

\begin{abstract}
Özet
Amaç. Çalışmamızda; izole Koroner Arter Bypas Greft Operasyonu (KABGO) uygulanmış hastalarda, preoperatif MPV değerleri ile postoperatif serebrovasküler olay (SVO) arasındaki ilişki araştırıldı. Yöntem. Ocak 2010 ve Haziran 2014 arasında Kalp ve Damar Cerrahisi Kliniği'nde KABGO yapılmış 265 hasta çalışmaya alınmıştır. Homojen bir çalışma grubu oluşturmak için; diyaliz giren, kreatinin seviyeleri $2 \mathrm{mg} / \mathrm{dL}$ 'nin üstünde olan, operasyon içerisinde aortada makroskopik patoloji tespit edilen ve bu sebeple operasyon prosedüründe değişiklik yapılan hastalar ile acil statüsünde ve re-do operasyona alınan hastalar çalışmaya dahil edilmemiştir. Çalışmadaki bütün hastalara izole KABGO (kros klemp kullanılarak on-pump veya pompa destekli beating heart veya beating heart) yapılmıştır. Hastaların hepsinde kros klemp süreleri 70 dakikayı, kardiyopulmoner bypass süreleri 120 dakikayı geçmemiştir. Preoperatif dönemde çalışmaya katılan hastaların kan örnekleri, antikoagülan olarak etilen diamin tetra asetik asit (EDTA) bulunan standart tüplere alınmıştır. Toplanan bu örneklere, Sysmex KX-21N cihazı kullanılarak analiz yapılmış ve MPV değerleri elde edilmiştir. Bulgular. Çalışmaya katılan hastaların preoperatif MVP değerleri; Grup 1'de 7,04 \pm 0,5 Femtolitre (fL) (mean \pm standart sapma) iken, Grup 2'de 9,05 \pm 1,3 fL olduğu tespit edildi. Sonuç. Yapılan istatiksel analizde, preoperatif yüksek MPV değerleri ile postoperatif SVO arasında anlamlı ilişki olduğu tespit edilmiştir $(\mathrm{p}<0,05 ; \mathrm{p}=0,028)$.
\end{abstract}

Anahtar sözcükler: KABGO, ortalama trombosit hacmi (mpv), inme

\begin{abstract}
Aim. In our study; we researched relation between preoperative MPV values and postoperative SVO in patients who underwent isolated CABG surgery. Metohds. 265 patients who underwent isolated CABG surgery in depertmant of Cardiovascular Surgery between January 2010 and June 2014 , were taken in this study. Because of homogeneous study group was constituted, this study do not include patients who patients with dialysis, patients have creatinin level $>2 \mathrm{mgr} / \mathrm{dL}$, patients who plaque were showed on aortic wall in this causes changes operation style, patiens underwent emergency surgery. All patients in our study were performed CABG (on-pump with cross clamp or pump support beating heart or beating heart) surgery. All patients cross clamp and cardiopulmonary bypass times less than $70 \mathrm{~min}$. and $120 \mathrm{~min}$. In preoperative period, blood samples of all participants were taken with standart tubes including EDTA. Collected these samples were analysed with Sysmex KX-21N system and MPV values were determined. Results. Preoperative MPV values of patients who to be added in our study, in the group 1 was found mean \pm standart deviation $7.04 \pm 0.5$ Femtoliter (fL) while, in the group 2 was found mean \pm standart deviation $9.05 \pm 1.3 \mathrm{fL}$. Conclusion. According to was made statistically analysis, it was found significant relation between preoperative high MPV values and postoperative $\mathrm{SVO}(\mathrm{p}<0.05$, $\mathrm{p}=0.028)$.
\end{abstract}

Keywords: CABG, mean platalet volume, stroke

Geliş tarihi/Received: 08 Eylül 2014; Kabul tarihi/Accepted: 07 Aralık 2014

*İletişim adresi:

Dr. Fatih Aygün, Kalp ve Damar Cerrahisi Anabilim Dalı, Başkent Üniversitesi Konya Araştırma ve Uygulama Merkezi, TR-42000 Konya. E-posta: fatihaygun@ttmail.com 


\section{Giriș}

Trombositler normal homeostaziste önemli rol oynamaktadırlar ve ortalama trombosit hacmini gösteren mean platelet volume (MPV) değeri, trombosit fonksiyon kapasitesini belirtmektedir [1]. Büyük hacime sahip plateletler küçük hacime sahip plateletlere oranla daha fazla dens granüllerine sahiptirler. MPV'deki artış metabolik sendrom, strok ve diabetes mellitus (DM) sahibi hastalarda dökümante edilmiştir [2]. Birçok çalışmada MPV artışının; miyokardiyal infarkt, serebral iskemi ve transiyent iskemik atak için risk olduğu tespit edilmiştir [3-7]. Trombositlerin ateroskleroz patogenezinde önemli rol aldıkları da bilinmektedir. Bir çok çalışmada hiperkolesterolemi ile beraber trombositlerin aktivitelerinde artış bildirilmiştir [8].

Dünyada en fazla yapılan operasyonlardan birisi koroner arter bypass (KABGO) operasyonudur ve santral sinir sistemi komplikasyonlarını içermektedir. Serebral zedelenme KABGO'nun önemli bir komplikasyonudur. KABGO sonrasi serebral komplikasyon hızı ve risk faktörleri araştırılmıştır [9-13]. Birçok çalışma, kardiyopulmoner bypass (CPB) esnasinda serebral zedelenmenin etyolojisinde multipl risk faktörlerinin olduğunu belirtmektedir [14, 15]. KABGO sonrası nörolojik bozulma hipoksiye, emboliye, kanamaya ve metabolik anormalliklere bağlanmaktadır [16, 17]. Kardiyak cerrahideki birçok gelişmeye rağmen stroke bir problem olarak kalmıştır.

KABGO uygulanmış hastalarda, preoperatif MPV değeri ile postoperatif serebrovasküler olay (SVO) arasındaki ilişki araştırılmıştır.

\section{Gereç ve yöntem}

\section{Hastaların dĕgerlendirilmesi}

Bu çalışma; kliniğimizde ocak 2010 ve haziran 2014 tarihleri arasında, koroner arter bypas greft operasyonu (KABGO) geçirmiş toplam 265 kişiyi içermektedir. Bu tarihler arasında dışlanma kriterleri ugulandıktan sonra kalan ardışık hastalardan oluşmaktadır. Homojen bir grup oluşturmak için; diyaliz hastası veya kreatinin seviyeleri 2 gr/dL'nin üstündeki hastalar, operasyon içerisinde aortada patoloji tespit edilen ve bu sebeple operasyon prosedüründe değişiklik yapılan hastalar, acil statüsünde operasyona alınan hastalar, redo-KABGO uygulanan hastalar çalışmaya dahil edilmemiştir. Veriler retrospektif olarak toplanmıştır. Çalışmaya katılan bireylerin MPV ortalaması hesaplandı ve bu ortalamaya göre iki gruba ayrıldı. MPV $<7,9 \mathrm{fL}$ ise Grup 1, MPV $\geq 7,9 \mathrm{fL}$ ise Grup 2 olarak kabul edildi. Tüm hastaların operasyon öncesi tıbbi geçmişi sorgulanmış, fizik muayeneleri ayrıntılı biçimde yapılmıştır. Preoperatif dönemde Kardiyovasküler Cerrahi (KVC) kliniğinde standart preoperatif labaratuar tetkikleri, solunum fonksiyon testi (Spirobank Spirometry, MIR medical International Research Product), transtorasik ekokardiyografi (TTE) (Acuson, Mountain View, Acuson Sequoia C256), billateral karotid arter doppler ultrasonogrofi (Toshiba XARIO primeultrasound) uygulanmıştır. Operasyondan önce standart telegram ile asendan ve arkus kalsifikasyonu değerlendirilmiştir.

Preoperatif dönemde, On-Pump (cross-clamp uygulanmış) CABG uygulanacak vakaların; klopidogrel (eğer kullanıyorsa) kullanımı operasyon tarihinden 5 gün önce, asetilsalisilik asit kullanımı operasyon tarihinden 1 gün önce kesilmiştir. Off-Pump (Beating-heart) CABG uygulanacak vakaların; klopidogrel (eğer kullanıyorsa) kullanımı operasyon tarihinden 5 gün önce, asetilsalisilik asit kullanımı operasyon tarihinden 1 gün önce kesilmişsir.

Operasyon esnasında asendan aorta ve arkus başlangıcı manuplasyonla dikkatli bir şekilde muayene edilmiştir. Manuplasyonda plak tespit edilen hastalarda, prosedür değişikliği yapılmış ve çalışmaya dahil edilmemiştir. Çalışmaya katılan hastalara üç farklı teknikle KABGO yapılmıştır. Birincisi; CPB ile kros klemp kullanarak KABGO, ikincisi; $\mathrm{CPB}$ desteğinde beating heart tekniği ile $\mathrm{KABGO}$, üçüncüsü; Beating heart tekniği ile KABGO yapılmıştır. Tüm vakalarda side klemp kullanılarak proksimal anastamozlar gerçekleştirilmiştir. 
CPB ve kros klemp tekniği ile KABGO yapılan vakaların krosklemp süreleri 70 dakikayı, kardiyopulmoner bypass süreleri 120 dakikayı geçmemiştir.

Postoperatif dönemde; KABGO sonrası stroke riskini azaltması sebebiyle çalışmadaki bütün hastalara enteral beslenmeyle beraber $300 \mathrm{mg} /$ gün asetilsalisilik asit başlanmıştır [31]. Diyabeti olan vakalarda, kan glukoz regülasyonu operasyon öncesi ve sonrasında regüler insülin ile gerçekleştirilmiştir. Hastaların kan glukoz seviyeleri 200 mg/dL altında tutulmuşstur.

\section{Cerrahi prosedür}

Çalışmaya katılan bütün hastalara, ilk izole KABGO operasyonu yapıldı. Anestezi indüksiyonunda fentanyl, midozolam, pancuronium bromid verildi. Standart median sternotomi uygulandı. LIMA, diğer vascular konduitler (safen ve radial arter) hazırlandi. $300 \mathrm{IU} / \mathrm{kg}$ heparin verildi. CPB ve kros klemp, standart aortic ve two stage venous kanül kullanıldı. Roller pompa ile CPB'ye başlandı. Bütün hastalara, operasyon esnasında kristaloid kardiyopleji, bitiminde hot shot kardiyopleji verildi. Sol internal mammarian arter (LIMA) vakaların hepsinde kullanılırken, sağ internal mammarian arter kullanılmadı. Operasyonlarda metikülos aseptik teknik uygulandı. Gereksiz elektrokoter kullanımından ve CPB'de lüks perfüzyondan (gereksiz, tromboemboli riskini arttıran perfüzyon) kaçınıldı. Beating heart tekiniği uygulanan hastlarda, $150 \mathrm{IU} / \mathrm{kg}$ heparinizasyon uyguland. Octopus ve Starfish kullanilarak distal anastamozlar gerçekleştirildi. Gerek on-pump gerekse off-pump tekniğinde, aortaya anastamozlar side klemp eşliğinde yapıldı. Operasyonla ilgili bazı veriler Tablo 2'de verilmiştir.

Tablo 1. Gruplara ait veriler.

\begin{tabular}{|c|c|c|c|}
\hline & Grup $1(n=144)(M P V<7,9)$ & Grup $2(n=121)(M P V \geq 7,9)$ & p değeri \\
\hline MPV & $7,04 \pm 0,5$ & $9,05 \pm 1,3$ & $<0,001 *$ \\
\hline Yaş $( \pm \mathrm{SD})(\mathrm{y} 1 \mathrm{l})$ & $62,2 \pm 10,1$ & $63.8 \pm 9.8$ & $0,204 *$ \\
\hline Cinsiyet (erkek) & $105(\% 72,9)$ & $70(\% 57,9)$ & $0,010 \dagger$ \\
\hline Sigara kullanımı & $65(\% 45,1)$ & $40(\% 33,1)$ & $0,045 \dagger$ \\
\hline $\mathrm{KOAH}$ & $28(\% 19,4)$ & $26(\% 21,5)$ & $0,681 \uparrow$ \\
\hline Hipertansiyon & $112(\% 77,8)$ & $100(\% 82,6)$ & $0,324 \dagger$ \\
\hline Periferik arter hastalığ 1 & $8(\% 5,6)$ & $5(\% 4,1)$ & $0,593 \dagger$ \\
\hline Preoperatif SVO hikayesi & $7(\% 4,9)$ & $10(\% 8,3)$ & $0,260 \dagger$ \\
\hline Diyabet oral a/d, parenteral a/d & $34(\% 23,6), 22(\% 15,3)$ & $40(\% 33,1), 26(\% 21,5)$ & $0,039 \dagger$ \\
\hline \multicolumn{4}{|l|}{ Sağ karotid arter } \\
\hline lezyon<\%50 & $45(\% 31,3), 3(\% 2,1)$ & $39(\% 32,2), 9(\% 7,4)$ & $0.156 \dagger$ \\
\hline$\% 50<$ lezyon $\leq \% 70$ & $0(\% 0)$ & $1(\% 0,8)$ & \\
\hline$\% 70 \leq$ lezyon $<\% 100$ & $1(0,7)$ & $0(\% 0)$ & \\
\hline lezyon $<\% 100$ & & & \\
\hline \multicolumn{4}{|l|}{ Sol karotid arter } \\
\hline lezyon $<\% 50$ & $41(\% 28,5), 6(\% 4,2)$ & $43(\% 35,5), 7(\% 5,8)$ & $0,363 \dagger$ \\
\hline$\% 50<$ lezyon $\leq \% 70$ & $2(\% 1,4)$ & $0(\% 0)$ & \\
\hline$\% 70 \leq$ lezyon $<\% 100$ & $1(\% 0,7)$ & $2(\% 1,7)$ & \\
\hline \multicolumn{4}{|l|}{ lezyon $=\% 100$} \\
\hline Kilo(kg) & $79,5 \pm 13,9$ & $76,6 \pm 12,8$ & $0,081 *$ \\
\hline Vücut yüz ölçümü $\left(\mathrm{m}^{2}\right)$ & $1,89 \pm 0,1$ & $1,85 \pm 0,2$ & $0,161 *$ \\
\hline Ejeksiyon fraksiyon & $54,2 \pm 9,4$ & $53, \pm 9,3$ & $0,492 *$ \\
\hline Preoperatif trombosit sayısı & $269,5 \pm 74,9$ & $243,1 \pm 86,4$ & $0,008 *$ \\
\hline Postoperatif SVO & $0(\% 0)$ & $4(\% 3,3)$ & $0,028 \dagger$ \\
\hline
\end{tabular}

Tablo 2. Hastaların operatif verileri.

\begin{tabular}{|c|c|c|c|}
\hline & Grup $1(n=144)($ MPV $<7,9)$ & Grup $2(n=121)(M P V \geq 7,9)$ & p değeri \\
\hline Bypas greft sayısı & $3.1 \pm 1$ & $3,3 \pm 1$ & $0,246 *$ \\
\hline Side klemp kullanılan & $138(\% 95,8)$ & $119(\% 98,3)$ & $0,234 \dagger$ \\
\hline CPB $+\mathrm{X}$ klemp kullanılan & $84(58,3)$ & $86(\% 71,1)$ & $0,031 \dagger$ \\
\hline $\begin{array}{l}\text { CPB desteğinde beating } \\
\text { heart }\end{array}$ & $1(0,7)$ & $5(\% 4,1)$ & $0,061 \dagger$ \\
\hline Beating heart & $59(\% 41)$ & $30(\% 24,8)$ & $0,005 \dagger$ \\
\hline
\end{tabular}




\section{Postoperatif bakım}

Ameliyat sonrası dönemde normal koşullar altında; KABGO sonrası komplikasyon riskini azaltması sebebiyle, çalışmadaki bütün hastalarımıza enteral beslenmeyle beraber $300 \mathrm{mg} /$ gün asetil salisilik asit $\left(\right.$ Coraspin $300^{\circledR}$ ) başlandı. Kliniğimizde standart profilaktik antibiyotik olarak kullanılan cefazolin sodium (Cefamezin ${ }^{\circledR}$-IM/IV) operasyondan 30 dak. önce 1 gr. ve operasyondan sonra 8 saatte 1 gr. olacak şekilde 72 saat devam edildi. Diyabetik hastalarda kan glukoz regülasyonu; operasyon sonrasında, insulin glargine $100 \mathrm{IU} / \mathrm{mL}$ (Lantus ${ }^{\circledR}$ flacon) ve human soluble regular insulin 100 $\mathrm{IU} / \mathrm{mL}$ (Humulin- $\mathrm{R}^{\circledR}$ flacon) ile katı bir şekilde gerçekleştirildi. İhtiyaç durumunda insülin infüzyonundan kaçınılmadı. Bütün diyabetik hastaların kan glukoz seviyeleri 200 $\mathrm{mg} / \mathrm{dL}$ altında tutuldu.

Postoperatif dönemde hastalar; operasyon günü KVC yoğun bakımında 48 saat kaldıktan sonra, üçüncü 24 saat içerisinde drenleri ve arteriyel kateterleri çekilip, KVC servisine alındı. KVC servisinde posteperatif 4'üncü günü santral damar yollu alındı. Hastalar postoperatif 6-11'inci günler arasında taburcu edildi ve operasyondan sonraki 60 gün SVO açısından takip edildi.

\section{Trombosit sayısı ve ortalama trombosit hacmi (MPV)}

Preoperatif dönemde çalışmaya katılan hastaların kan örnekleri, antikoagülan olarak etilen diamin tetra asetik asit (EDTA) bulunan standart tüplere alındı. Toplanan bu örneklere, Cell-Dyne 3700 (Abbott, Abbott Park, IL, USA) cihazı kullanılarak analiz yapıldı ve MPV değerleri elde edildi. Çalışmaya katılan bireylerin MPV ortalaması alındı ve bu ortalamaya göre iki gruba ayrıld1. MPV $<7,9 \mathrm{fL}$ ise Grup 1, MPV $\geq 7,9 \mathrm{fL}$ ise Grup 2 olarak kabul edildi.

\section{Ístatiksel analiz}

İstatistiksel analizler SPSS programı (SPSS Inc., Chicago, IL, USA) ile yapıldı. Gruplar arası; görülme sıklığı olarak değerlendirilen verilerin istatiksel anlamlılığı Pearson KiKare analizi ile incelendi. Rakamsal olarak ifade edilen veriler minimum, maksimum, ortalama \pm standart sapma olarak gösterilirken, gruplar arası bu verilerin istatiksel anlamlılı̆g 1 independent student $t$ testi ile araştırıldı. Two-tailed $p$ değeri 0,05 'in altında $(\mathrm{p}<0,05)$ ise sonuç istatistiksel olarak anlamlı kabul edildi (Tablo 1, 2). Cinsiyet, sigara kullanımı, Tip 2 diyabet varlığı, preoperatif trombosit sayısı, beating heart tekniği ile operasyon yapılan hasta sayısı, CPB X-Klemp uygulanmış hasta sayısı açısından gruplar eşit tutulamamıştır. Bu verilerin postoperatif SVO ile ilişkisisi Lojistik regresyon analizi ile araştırılmıştır (Tablo 3).

Tablo 3. Gruplar arasında istatiksel farklı olan $(p<0,05)$ parametreler ile postoperatif görülen SVO için Lojistik regresyon analizi yapılmıştır.

\begin{tabular}{|c|c|c|c|c|}
\hline & Wald & $\% 95 \mathrm{CI}$ & OR & p değeri \\
\hline Cinsiyet & 0,187 & $0,054-6,478$ & 0,590 & 0,666 \\
\hline Sigara kullanımı & 0,141 & $0,242-3,342$ & 0,603 & 0,708 \\
\hline $\begin{array}{l}\text { Tip } 2 \text { diyabet } \\
\text { varl } \breve{g ̆ g}_{1}\end{array}$ & 0,025 & $0,043-8,486$ & 0,900 & 0,875 \\
\hline $\begin{array}{l}\text { Preoperatif } \\
\text { trombosit sayıs1 }\end{array}$ & 0,169 & $0,989-1,017$ & 1,003 & 0,681 \\
\hline $\begin{array}{l}\text { CPB+X klemp } \\
\text { kullanılan hasta } \\
\text { sayıs1 }\end{array}$ & 0 & 0 & 0 & 0,999 \\
\hline $\begin{array}{l}\text { Beating heart } \\
\text { tekniği kullanılan } \\
\text { hasta sayısı }\end{array}$ & 0 & 0 & 1,003 & 1,000 \\
\hline
\end{tabular}




\section{Bireylerin karakteristiği}

Çalışmaya katılan tüm bireylerin yaş dağılımı; minimum (min.) 27 yıl (y), maksimum (max.) 89 yıldır (ortalama \pm standart sapma 62,9 \pm 9,9 y). Bu kişilerin 175'i (\%66) erkek, 90’1 (\%34) kadındır. Hipertansiyonlu (HT) hasta sayıs1 212 (\%80), antidiyabetik ajan kullananların sayısının 122 (\%46), olduğu görüldü. Sigara kullanan 105 (\%39,6), kişi tespit edildi. SVO geçirmiş hasta sayıs1 $17(\% 6,4)$, sağ karotid arterde darlık $(\% 70 \leq$ lezyon $<\% 100)$ olan hasta sayıs1 $1(\% 0,4)$, sol karotid arterde darlik $(\% 70 \leq$ lezyon $<\% 100)$ olan hasta sayısı $2(\% 0,8)$ olarak tespit edildi. Çalışmaya katılanlar arasında; Mean Platalet Volume (MPV) min.: 3,7 fL, max.: 18,2 fL (ortalama \pm standart sapma 7,9 $\pm 1,43 \mathrm{fL}$ ) olarak bulundu. KABGO sonrası Tip I nörolojik defisit 4 hastada saptandı.

\section{MPV'ye göre grupların karakteristiği}

Grup 1'deki erkeklerde; MPV ortalaması 6,99 $\pm 0,6 \mathrm{fL}$, yaş ortalaması $61,3 \pm 10 \mathrm{y}$, daha

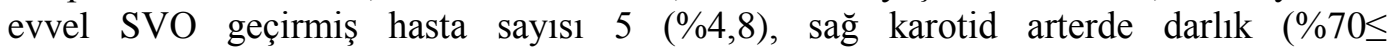
lezyon $<\% 100)$ olan hasta sayıs1 $0(\% 0)$, sol karotid arterde darlık $(\% 70 \leq$ lezyon $<\% 100)$ olan hasta sayıs1 $2(\% 1,9)$ olarak tespit edildi. Sigara kullanan $62(\% 59)$, hipertansiyonlu $75(\% 71,4)$, kronik obstriktif akciğer hastalığ kullanan $25(\% 23,8)$ paranteral antidiyabetik kullanan $9(\% 8,6)$ kişi olduğu görüldü.

Grup 1'deki bayanlarda; MPV ortalaması 7,17 $\pm 0,4 \mathrm{fL}$, yaş ortalaması 64,7 $\pm 9,8 \mathrm{y}$, daha evvel SVO geçirmiş hasta sayıs1 $2(\% 5,1)$, sağ karotid arterde darlık $(\% 70 \leq$ lezyon $<\% 100)$ olan hasta sayisı $0(\% 0)$, sol karotid arterde darlık (\%70 lezyon <\%100) olan hasta sayıs $0(\% 0)$ olarak tespit edildi. Sigara kullanan $3(\% 7,7)$, hipertansiyonlu 37 $(\% 94,9)$, KOAH’l1 $8(\% 20,5)$, oral antidiyabetik kullanan $9(\% 23,1)$ paranteral antidiyabetik kullanan $13(\% 33,3)$ kişi olduğu görüldü.

Grup 2'deki erkeklerde; MPV ortalaması 8,90 $\pm 1,3 \mathrm{fL}$, yaş ortalaması 63,8 $\pm 10,5 \mathrm{y}$, daha evvel SVO geçirmiş hasta sayısı $9(\% 12,9)$, sağ karotid arterde darlık (\%70 lezyon

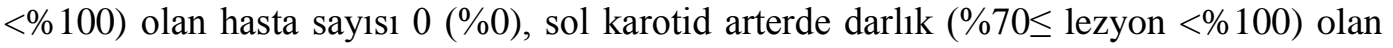
hasta sayıs1 $0(\% 0)$ olarak tespit edildi. Sigara kullanan $36(\% 51,4)$, hipertansiyonlu 55 $(\% 78,6)$, KOAH'l1 $13(\% 18,6)$, oral antidiyabetik kullanan $22(\% 31,4)$ paranteral antidiyabetik kullanan $9(\% 12,9)$ kişi olduğu görüldü.

Grup 2'deki bayanlarda; MPV ortalaması 9,26 $\pm 1,4 \mathrm{fL}$, yaş ortalaması 63,8 $\pm 8,8 \mathrm{y}$, daha evvel SVO geçirmiş hasta sayısı $1(\% 2)$, sağ karotid arterde darlık (\%70 lezyon <\%100) olan hasta sayıs1 $1(\% 2)$, sol karotid arterde darl1k (\%70 lezyon $<\% 100)$ olan hasta sayıs $0(\% 0)$ olarak tespit edildi. Sigara kullanan $4(\% 7,8)$, hipertansiyonlu $45(\% 88,2)$, KOAH'l1 $13(\% 25,5)$, oral antidiyabetik kullanan $18(\% 35,3)$ paranteral antidiyabetik kullanan $17(\% 33,3)$ kişi olduğu görüldü.

Hastalar postoperatif 60 güne kadar SVO açısından takip edildi. İki hastada iskemik optik nörit, bir hastada transiyent iskemik atak, bir hastada sol hemipleji olmak üzere toplam 4 adet SVO vakası mevcuttur. Postoperatif SVO görülen bu 4 hastada, iki vakada Tip 2 diyabet hastalığ 1 varken, 2 vakada Tip 2 diyabet hastalı̆̆ yoktu.

\section{Tartışma}

Nörolojik anormalliklerin KABGO sonrası görülmesi korkutucu bir komplikasyondur. İnsidans1 \%0,4'ten \%80'e kadar neye bağlı olarak tanımlandığına göre değişmektedir [1920]. CABG sonrası nörolojik defisit 2 tipe ayrılmaktadır: Tip 1 defisit yıkıc1, fokal motor kayıp, stupor ve koma ile karakterize iken, Tip 2 defisit entelleküel fonksiyonda ve hafizada dezoryantasyon ile karakterizedir.

Roach ve ark. [10] KABGO sonrası Tip 1 (stroke) ve Tip 2 (ensefalopati) defisitin gerçek insidansını belirlemek için çok merkezli prospektif bir çalışmayı bildirmişlerdir. Bildirdikleri çalışmada, 24 merkezde 2108 hasta opere edilmiş ve KABGO sonras1 nörolojik açıdan gözlemlenmiştir. 129 hastada $(\% 6,1)$ cerebral komplikasyon görülmüş; Tip $1(\% 3,1)$ ve Tip $2(\% 3,0)$ oranları bulunmuştur. 
Mortaliteyle bu komplikasyonlar arasında Tip 1 defisit için \%21, Tip 2 defisit için $\% 10$ birliktelik bulunmuştur.

KABGO sonrası nörolojik komplikasyonun sağlık harcamasını arttırması da söz konusudur. Amerika Birleşik Devletler'inde yapılan bir araştırmaya göre; nörolojik komplikasyonu olan hastaların hastanede kalırken 2 kat fazla, 6 kat fazla da ev bakım hizmeti almak zorunda kaldığı tespit edilmiştir.

Plateletler, aterosklerotik komplikasyonların patogenezinde çok önemli role sahiptirler [21]. MPV platelet fonksiyon belirtecidir. Büyük plateletler daha fazla dens granüllerine sahiptirler ve daha fazla tromboksan A2 üretirler. MPV'nin yükselmesi, adenozin difosfat (ADP) ve kollejene bağlı artmış in vitro agregasyonla ilişkilidir [22]. Artmış platelet boyutları; diyabet, hiperkolesterolemi, tütün kullanımı ve renal arter stenozlu gibi vasküler riskli hastalarda rapor edilmiştir [23-26]. Birçok çalışmada akut iskemik stroklu hastalarda kontrol grubuna göre yüksek seviyeli MPV değerleri bulunmuştur. Trombosit fonksiyonlarının bir göstergesi olarak kabul edilen MPV'nin; trombosit aktivitesini değerlendirerek, iskemik strokun akut dönemindeki değişiminin bilinmesinde yararlı olacağını belirten çalışma mevcuttur [27].

İlaçların platelet hacimlerine olan etkisi az bilinmektedir. Önceki in vitro çalışmalar asetilsalisilik asitin MPV'yi etkilemediğini gösterirken, klopidogrelin MPV artışını inhibe ettiğini belirtmektedir. Losartan, doksazosin, lipid düşürücü gibi ilaçların da platelet hacmini etkilediğini gösteren yayınlar mevcuttur [28-30)]. KABGO öncesi bu ilaçların standart olarak kesilmiş olması çalışmamızın daha objektif olmasını sağlamaktadır. Preoperatif dönemde kesilen ace inhibitörleri, antiplatelet tedavi postoperatif dönemde başlanmıştır.

Önceki çalışmalar antikoagülan olarak kullanılan EDTA'nın MPV değerlerini arttırdığını rapor ederken, son zamanlardaki yayınlar hastadan alınan kan örneğinin 2 saat içerisinde çalışıldığ kan örnekleri EDTA içeren standart tüplere alınmış ve alındıktan sonra 2 saat içerisinde analiz edilmiştir.

Cerrahi sonrası stroke hiç istenmeyen bir komplikasyon olmasına rağmen, bazı hastalar için kaçınılmaz sonuç olmaktadır. KABGO öncesi dönemde mortalite risk yüzdesinin tahmin edilmesi için, Amerikan Kalp Cemiyeti (ACC/AHA) hastaya ait birçok verinin (yaş, karotid arter darlığı vb.) puanlandırılmasıyla oluşan, risk skorlama metodu geliştirmiştir. Fakat preoperatif bu skorlamanın içerisinde MPV bulunmamaktadır. Cerrahlar operasyon öncesi hastayı değerlendirirken MPV'ye dikkat etmemektedirler. Daha önce yapılmış yayınlarda MPV yüksekliğinin inme ve diğer serebro vasküler olaylarla bağlantısı bulunduğunu gösteren sonuçların mevcut olması çalışmamızın temelini oluşturmuştur.

$\mathrm{Bu}$ çalışmada amacımız KABGO yapılacak hastalarda preoperatif dönemde MPV yüksekliğinin, postoperatif SVO açısından prediktif değerini araştırmaktı. MPV'nin; KABGO sonrası yıkıcı ve maliyet arttırıc1 komplikasyon olan SVO'yu önceden belirten bir parametre olabileceğini düşündük. KABGO uygulanmış hastalarda, preoperatif MPV $\geq 7,9$ fL olan Grup 2'de, preoperatif MPV <7,9 fL olan Grup 1'e göre, post operatif SVO görülmüş ve aradaki fark istatiksel olarak anlamlı bulundu. ( $<<0,05 ; p=0,028)$.

Birçok özelliğe sahip hasta popülasyonunda; cinsiyet, sigara kullanımı, diyabet, preoperatif trombosit sayısı ve ameliyat prosedürleri açılarından, her iki grubu benzer tutmak mümkün olmamıştır.

Gruplar arasında istatisel farkl1lik bulunan cinsiyet, sigara kullanım1, Tip 2 diyabet varlığı, preoperatif trombosit sayısı, beating heart tekniği ile operasyon yapılan hasta sayısı, CPB X-Klemp uygulanmış hasta sayısı açısından lojistik regresyon analizi yapılmış ve postoperatif SVO açısından ilişki tespit edilmemiştir (Tablo 3). 
Sonuç olarak; elde ettiğimiz veriler ışığında, operasyon öncesi MPV yüksekliklerinin, koroner bypass ameliyatı sonrasındaki SVO açısından öngörü kazandırdığı inancındayız. $\mathrm{Bu}$ konuda kesin bulgular için daha geniş hasta serileri ile ileri çalışmaların yapılması gerektiği düşüncesindeyiz.

\title{
Kisaltmalar
}

1. KABGO : Koroner arter bypas greft operasyonu

2. MPV

3. $\mathrm{KOAH}$

4. SVO

5. $\mathrm{fL}$

\author{
: Ortalama trombosit hacmi \\ : Kronik obstriktif akciğer hastalı̆̆1 \\ : Serebrovasküler olay \\ : Femtolitre
}

*Teşekkür: Çalışmamızda; istatiksel analizde vermiş olduğu katkılardan dolayı Konya Selçuk Üniversitesi, Biyometri ve Genetik Anabilim Dalı öğretim üyesi Doç. Dr. İsmail Keskin'e teşekkür ederiz.

\section{Kaynaklar}

1. Jakubowski JA, Thompson CB, Vaillancourt R, Valeri CR, Deykin D. Arachidonic acid metabolism by platelets of differing size. Br J Haematol 1983; 53: 503-11.

2. Tavil Y, Sen N, Yazici HU, Hizal F, Abaci A, Cengel A. Mean platelet volume in patients with metabolic syndrome and its relationship with coronary artery disease. Thromb Res 2007; 120: 245-50.

3. Khandekar MM, Khurana AS, Deshmukh SD, Kakrani AL, Katdare AD, Inamdar AK. Platelet volume indices in patients with coronary artery disease and acute myocardial infarction: An Indian scenario. J Clin Pathol 2006; 59: 146-9.

4. Kiliçli-Camur N, Demirtunç R, Konuralp C, Eskiser A, Başaran Y. Could mean platelet volume be a predictive marker for acute myocardial infarction? Med Sci Monit 2005; 11: 387-92.

5. Nadar SK, Lip GY, Blann AD. Platelet morphology, soluble P selectin and platelet P-selectin in acute ischaemic stroke. The West Birmingham Stroke Project. Thromb Haemost 2004; 92: 1342-8.

6. McCabe DJ, Harrison P, Sidhu PS, Brown MM, Machin SJ. Circulating reticulated platelets in the early and late phases after ischaemic stroke and transient ischaemic attack. Br J Haematol 2004; 126: 861-9.

7. O'Malley T, Langhorne P, Elton RA, Stewart C. Platelet size in stroke patients. Stroke 1995; 26: 995-9.

8. Altunbaş, A. Odabaşoğlu, M. Kemal Balc1, G. Günay, İ. Karadoğan, L. Ündar, Ü. Karayalçın. The Effect of Simvastatin on in vitro Platelet Aggregation in Hypercholesterolemic Patients. H. Turkiye Klinikleri J Med Sci 1999; 19: 25-9.

9. Breuer AC, Furlan AJ, Hanson MR, Lederman RJ, Loop FD, Cosgrove DM, Greenstreet RL, Estafanous FG. Central nervous system complications of coronary artery bypass graft surgery: prospective analysis of 421 patients. Stroke 1983; 14: 682-7.

10. Coffey CE, Massey EW, Roberts KB, Curtis S, Jones RH, Pryor DB. Natural history of cerebral complications of coronary artery bypass graft surgery. Neurology 1983; 33: 1416-21.

11. Roach GW, Kanchuger M, Mangano CM, Newman M, Nussmeier N, Wolman R, Aggarwal A, Marschall K, Graham SH, Ley C, Ozanne G, Mangano DT. Adverse cerebral outcomes after coronary bypass surgery. N Engl J Med 1996; 335: 1857-63.

12. Gardner TJ, Horneffer PJ, Manolio TA, Pearson TA, Gott VL, Baaumgartner WA, Borkon AM, Watkins L Jr, Reitz BA. Stroke following coronary artery bypass grafting: a ten year study. Ann Thorac Surg 1985; 40: 574-81.

13. Herlitz J, Wognsen GB, Haglid M, Hartford M, Hjalmarson A, Karlson BW. Risk indicators for cerebrovascular complications after coronary artery bypass 
grafting. Thorac Cardiovasc Surg 1998; 46: 20-4.

14. Tuman KJ, McCarthy RJ, Najafi H, Ivankovich AD. Differential effects of advanced age on neurologic and cardiac risks of coronary artery operations. $\mathbf{J}$ Thorac Cardiovasc Surg 1992; 104: 1510-7.

15. Lynn GM, Stefanko K, Reed JF, Gee W, Nicholas G. Risk factors for stroke after coronary artery bypass. J Thorac Cardiovasc Surg 1992; 104: 1518-23.

16. Harrison MJ. Neurologic complications of coronary artery bypass grafting: diffuse or focal ischemia? Ann Thorac Surg 1995; 59: 1356-8.

17. Hornick P, Smith PL, Taylor KM. Cerebral complications after coronary bypass grafting. Curr Opin Cardiol 1994; 9: 670-9.

18. Breuer AC, Furlan AJ, Hanson MR, Lederman RJ, Loop FD, Cosgrove DM, Greenstreet RL, Estafanous FG. Central nervous system complications of coronary artery bypass graft surgery: prospective analysis of 421 patients. Stroke 1983; 14: 682-7.

19. Furlan AJ, Breuer AC. Central nervous system complications of open heart surgery. Stroke 1984; 15: 912-5.

20. Ross R. Atherosclerosis: an inflammatory disease. N Engl J Med 1999; 340:11526.

21. Smith NM, Pathansali R, Bath PM. Platelets and stroke. Vasc Med 1999; 4: 16572.

22. Tschoepe D, Esser J, Schwippert B, Rosen P, Kehrel B, Niewuenhuis HK, Gries FA. Large platelets circulate in an activated state in diabetes mellitus. Semin Thromb Hemost 1991; 17: 433-9.

23. Kario K, Matsuo T, Nakao K. Cigarette smoking increases the mean platelet volume in elderly patients with risk factors for atherosclerosis. Clin Lab Haematol 1992; 14: 281-7.

24. Bath PM, Butterworth RJ. Platelet size: measurement, physiology and vascular disease. Blood Coagul Fibrinolysis 1996; 7: 157-61.

25. Bath PM, Missouris CG, Buckenham T, MacGregor GA. Increased platelet volume and platelet mass in patients with atherosclerotic renal artery stenosis. Clin Sci 1994; 87: 253-7.

26. Taşkın D, Ferhan K, Şeref K, Sabahat G. Mean platelet volume and platelecrit in the acute ischemic stroke. Turkiye Klinikleri J Med Res 1994; 12: 249-52.

27. Jagroop IA, Mikhailidis DP. Angiotensin II can induce and potentiate shape change in human platelets: effect of losartan. J Hum Hypertens 2000; 14: 581-5.

28. Jagroop IA, Mikhailidis DP. Doxazosin, an alpha1-adrenoceptor antagonist, inhibits serotonin-induced shape change in human platelets. J Hum Hypertens 2001; 15: 203-7.

29. Milionis HJ, Elisaf MS, Mikhailidis DP. Platelets and lipid lowering interventions. Platelets 1999; 10: 357-67.

30. Smyth DW, Martin JF, Michalis L, Bucknall CA, Jewitt DE. Influence of platelet size before coronary angioplasty on subsequent restenosis. Eur J Clin Invest 1993; 23: 361-7.

31. Bath PM. The routine measurement of platelet size using sodium citrate alone as the anticoagulant. Thromb Haemost 1993; 70: 687-90. 